\title{
Job Mobility, Tenure, and Promotions in Political Science PhD-Granting Departments, 2002-2017: Cohort, Gender, and Citation-Count Effects
}

Hannah June Kim, University of California, Irvine

ABSTRACT Using updated data from 2002 and 2017 on the political science discipline, we show how the cohort and gender composition of US PhD-granting departments has changed dramatically over time. Integrating 2002 and 2017 data, we examine overall patterns and gender differences in job mobility, tenure and promotion, and university prestige level among non-emeritus 2002 faculty, controlling for cohort effects. Even with this control, we find strong gender effects in some of these success dimensions. We then introduce another variable, citation counts, and find that women are consistently less cited than men, with important variations in the pattern across different cohorts. A control for citation counts show that some of these gender differences tend to disappear and we consider possible explanations for these findings.

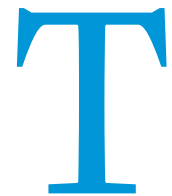

his research builds on and extends the database of 3,715 faculty created for "The Political Science 400: A 20-Year Update" by Masuoka, Grofman, and Feld (2007a) and used in subsequent work by these authors (Fowler, Grofman, and Masuoka 2007; Masuoka, Grofman, and Feld 2007 b; c), later updated by Kim and Grofman (2019; hereafter KG).1 The original Masuoka, Grofman, and Feld (hereafter MGF) dataset includes a record of all regular faculty members at the 132 US political science PhD-granting institutions ca. 2002 and provides supplementary information such as the date of $\mathrm{PhD}$, the institution from which the $\mathrm{PhD}$ was awarded, and individual faculty citation counts from 1965 to 2005,2 as well as gender coding. ${ }^{3}$ We build also on the KG (2019) update of the original MGF database that identifies where the original set of scholars are ca. 2017. We supplemented the original MGF and subsequent KG coding by including the rank currently held by individual faculty-based on our hand coding of departmental and individual websites-and the prestige level of departments. ${ }^{4}$

Hannah June Kim is a PhD candidate in political science at the University of California, Irvine. Her work on this project was supported by the Peltason Chair and the UCI School of Social Sciences. She can be reached at hannah.kim@uci.edu. Bernard Grofman iD the Jack W. Peltason (Bren Foundation Endowed) Chair of Democracy Studies and Distinguished Professor of Political Science at the University of California, Irvine. He can be reached at bgrofman@uci.edu.
Using these data, we asked related questions about indicia of professional success and correlating factors. Although our primary focus was on what has happened to faculty in the 2002 dataset who were still in non-emeritus status ca. 2017 in the intervening period, we also mention data in the 2017 faculty dataset. 5 We reviewed several overall indicators, looking particularly at the gender gap. ${ }^{6}$ However, before discussing the central questions of our investigation, we summarize descriptive information about our datasets. We found dramatic changes over time in the cohort and gender compositions of the PhD-granting departments.

A substantial proportion of those with jobs in $\mathrm{PhD}$-granting departments in 2002 are now either emeritus or deceased (33\%).7 Of those remaining, nearly $95 \%$ have stayed in academia with either a faculty appointment (93.4\%) or an administrative appointment (1.2\%). We found that roughly 90\% of this set remains at US PhD-granting institutions, the majority at the same institution they were listed at in 2002; 7.3\% have academic positions at US non-PhD-granting institutions; and $3 \%$ currently have jobs at academic institutions outside of the United States. ${ }^{8}$ Of these, more than $77 \%$ are full professors 9 and a non-trivial proportion of more than $22 \%$ who are 15 years or more past their $\mathrm{PhD}$ are still at the associate-professor rank or lower. ${ }^{10}$ Moreover, among this dataset, only $18 \%$ of male scholars remain at the associate-professor rank or lower whereas more than $33 \%$ of female scholars remain at the same level. 
Among those for whom we coded for gender in the full 2002 dataset, there were 2,930 (78.9\%) male scholars and 758 (21.1\%) female scholars. Among the tenured or tenure-track faculty at $\mathrm{PhD}$-granting departments in the 2017 dataset, moreover, there were 2,955 (72.3\%) male scholars and 1,135 (27.8\%) female scholars. This shows that the proportion of female faculty with $\mathrm{R} 1$ jobs is rising, albeit very slowly. there gender effects in terms of likelihood of achieving tenure or full-professor rank?

In addressing these questions, we were careful to consider differences in date of $\mathrm{PhD}$ (in terms of five-year cohorts). This control was especially critical in understanding gender differences in professional success because women currently comprise a higher proportion of job holders than in the past. Failure to use this control would

\section{Moreover, among this dataset, only $18 \%$ of male scholars remain at the associate-professor rank or lower whereas more than $33 \%$ of female scholars remain at the same level.}

We can see more clearly what has been happening to the gender composition of the profession by disaggregating the 2017 data into five-year cohorts. The proportion of female scholars teaching at $\mathrm{PhD}$-granting departments has grown steadily over time: the pre-1970 cohorts had female representation in the single digits; $12.88 \%$ of members in the $1970-1974$ cohorts were female; and the 1975-1999 cohorts had female representation in the $20 \%$ range. In the most recent (partial) cohort, women comprise $39.8 \%$ of faculty who have been hired (the full data are omitted due to limited space; see appendix J). ${ }^{11}$

Another important piece of descriptive data is information on the citation counts of faculty categorized by both cohort and gender. Table 1 shows average citation numbers for the full dataset of 2002 faculty, based on the Social Sciences Citation Index data reported by MGF.

The male-female citation ratio show that men are almost always cited more than women. Moreover-and rather surprisingly-the gap has increased over time. Similarly, the 2017 data set of political science faculty continues to show similar trends. ${ }^{12}$

\section{KEY QUESTIONS ABOUT GENDER DIFFERENCES}

For the non-emeritus 2002 faculty in 2017, we examined status changes during the intervening period. For example, if a faculty member changed institutions within the dataset of $\mathrm{PhD}$-granting departments, were there gender differences in whether the shift was to a PhD-granting department of greater prestige, of the same or lesser prestige, or to another type of job? Similarly, were risk confounding ecological compositional effects with causal patterns because men, on average, have had greater seniority due to historical gender gaps and thus are more likely to have higher rank and professional visibility.

We also considered the effects of controlling for citation counts, which we found to be an important factor in accounting for differences in various indicia of professional success. We discuss the impact of the interaction of citations and gender on professional success in a subsequent section. However, citations can be a gender-biased measure. Studies have shown that women are less likely to cite themselves than men (Maliniak, Powers, and Walter 2013); men are less likely to cite women scholars than male scholars (Maliniak, Powers, and Walter 2013); and edited books are disproportionately edited by men (with the striking exception of gender studies) (Mathews and Andersen 2001). ${ }^{13}$

\section{Status Change in Terms of Movement across Departments}

How likely were the non-emeritus 2002 faculty in 2017 to have made a change in jobs between 2002 and 2017 that involved an upward or downward movement in university ranking? Furthermore, is there a gender-related pattern to the directionality of change? Table 2 shows the proportion of non-emeritus scholars with an academic position in the United States who are currently at the same university that they were in 2002,14 categorized by gender. The table also provides data on those who moved to another academic position in the United States ca. 2017. For example, the table

Table 1

Average Citation Numbers for the 2002 Dataset of Faculty at Phd-Granting Departments By Cohort, Based on the Social Sciences Citation Index Data Reported By MGF

\begin{tabular}{|c|c|c|c|c|c|c|}
\hline Cohort & Average Citation \# & Average Female Citations & Average Male Citations & Female $\mathbf{N}$ & Male N & Male to Female Ratio \\
\hline $1960-64$ & 323.0 & 263.2 & 326.1 & 12 & 234 & 1.239 \\
\hline $1965-69$ & 287.1 & 241.3 & 292.0 & 39 & 368 & 1.210 \\
\hline 1970-74 & 287.6 & 310.0 & 284.5 & 59 & 431 & 0.918 \\
\hline 1975-79 & 247.7 & 235.3 & 251.0 & 88 & 332 & 1.067 \\
\hline $1980-84$ & 204.3 & 140.2 & 227.3 & 86 & 239 & 1.622 \\
\hline $1985-89$ & 115.4 & 90.2 & 124.2 & 94 & 268 & 1.377 \\
\hline 1990-94 & 71.0 & 47.2 & 81.4 & 149 & 342 & 1.724 \\
\hline 1995-99 & 34.5 & 23.8 & 39.8 & 177 & 353 & 1.675 \\
\hline Post-2000 & 13.3 & 10.9 & 15.0 & 69 & 90 & 1.375 \\
\hline
\end{tabular}


Table 2

Movement of 2002-2017 Non-Emeritus Faculty by PhD-Granting vs. Non-PhD-Granting, and University Rank Change for Those Staying at US R1 Institutions, with Further Breakdown by Gender

\begin{tabular}{|c|c|c|c|c|c|c|c|c|c|c|c|c|c|c|c|c|c|c|c|c|}
\hline \multirow[b]{2}{*}{ PhD Year } & \multicolumn{6}{|c|}{ Total } & \multicolumn{7}{|c|}{ Male } & \multicolumn{7}{|c|}{ Female } \\
\hline & $\#$ & + & - & Same & Diff. Dept. & Non-PhD & $\#$ & + & - & Same & Diff. Dept. & Non-PhD & Total & $\#$ & + & - & Same & Diff. Dept. & Non-PhD & Total \\
\hline Pre-1945 & 0 & $0 \%$ & $0 \%$ & $0 \%$ & $0 \%$ & $0 \%$ & 0 & $0 \%$ & $0 \%$ & $0 \%$ & $0 \%$ & $0 \%$ & $0 \%$ & 0 & $0 \%$ & $0 \%$ & $0 \%$ & $0 \%$ & $0 \%$ & $0 \%$ \\
\hline $1945-49$ & 0 & $0 \%$ & $0 \%$ & $0 \%$ & $0 \%$ & $0 \%$ & 0 & $0 \%$ & $0 \%$ & $0 \%$ & $0 \%$ & $0 \%$ & $0 \%$ & 0 & $0 \%$ & $0 \%$ & $0 \%$ & $0 \%$ & $0 \%$ & $0 \%$ \\
\hline $1950-54$ & 1 & $0 \%$ & $0 \%$ & $100 \%$ & $0 \%$ & $0 \%$ & 1 & $0 \%$ & $0 \%$ & $100 \%$ & $0 \%$ & $0 \%$ & $100 \%$ & 0 & $0 \%$ & $0 \%$ & $0 \%$ & $0 \%$ & $0 \%$ & $0 \%$ \\
\hline 1955-59 & 4 & $0 \%$ & $0 \%$ & $75 \%$ & $0 \%$ & $25 \%$ & 4 & $0 \%$ & $0 \%$ & $75 \%$ & $0 \%$ & $25 \%$ & $100 \%$ & 0 & $0 \%$ & $0 \%$ & $0 \%$ & $0 \%$ & $0 \%$ & $0 \%$ \\
\hline $1960-64$ & 39 & $23 \%$ & $10 \%$ & $85 \%$ & $0 \%$ & $3 \%$ & 39 & $3 \%$ & $10 \%$ & $85 \%$ & $0 \%$ & $3 \%$ & $100 \%$ & 0 & $0 \%$ & $0 \%$ & $0 \%$ & $0 \%$ & $0 \%$ & $0 \%$ \\
\hline $1965-69$ & 112 & $7 \%$ & $3 \%$ & $83 \%$ & $3 \%$ & $5 \%$ & 100 & $7 \%$ & $3 \%$ & $84 \%$ & $1 \%$ & $5 \%$ & $100 \%$ & 12 & $8 \%$ & $0 \%$ & $75 \%$ & $17 \%$ & $0 \%$ & $100 \%$ \\
\hline 1970-74 & 189 & $8 \%$ & $4 \%$ & $82 \%$ & $2 \%$ & $11 \%$ & 160 & $8 \%$ & $4 \%$ & $81 \%$ & $2 \%$ & $6 \%$ & $100 \%$ & 29 & $7 \%$ & $3 \%$ & $86 \%$ & $0 \%$ & $4 \%$ & $100 \%$ \\
\hline 1975-79 & 252 & $7 \%$ & $8 \%$ & $79 \%$ & $1 \%$ & $5 \%$ & 203 & $6 \%$ & $7 \%$ & $79 \%$ & $1 \%$ & $6 \%$ & $100 \%$ & 49 & $10 \%$ & $10 \%$ & $78 \%$ & $2 \%$ & $0 \%$ & $100 \%$ \\
\hline $1980-84$ & 241 & $6 \%$ & $8 \%$ & $81 \%$ & $1 \%$ & $33 \%$ & 186 & $6 \%$ & $9 \%$ & $80 \%$ & $1 \%$ & $4 \%$ & $100 \%$ & 55 & $7 \%$ & $4 \%$ & $86 \%$ & $2 \%$ & $2 \%$ & $100 \%$ \\
\hline $1985-89$ & 288 & $12 \%$ & $12 \%$ & $68 \%$ & $2 \%$ & $7 \%$ & 214 & $9 \%$ & $12 \%$ & $69 \%$ & $1 \%$ & $8 \%$ & $100 \%$ & 74 & $19 \%$ & $11 \%$ & $65 \%$ & $4 \%$ & $1 \%$ & $100 \%$ \\
\hline 1990-94 & 383 & $13 \%$ & $14 \%$ & $63 \%$ & $3 \%$ & $7 \%$ & 269 & $14 \%$ & $15 \%$ & $61 \%$ & $3 \%$ & $6 \%$ & $100 \%$ & 114 & $11 \%$ & $11 \%$ & $68 \%$ & $1 \%$ & $9 \%$ & $100 \%$ \\
\hline 1995-99 & 395 & $16 \%$ & $17 \%$ & $50 \%$ & $4 \%$ & $12 \%$ & 268 & $18 \%$ & $19 \%$ & $47 \%$ & $3 \%$ & $13 \%$ & $100 \%$ & 127 & $12 \%$ & $13 \%$ & $57 \%$ & $7 \%$ & $11 \%$ & $100 \%$ \\
\hline Post-2000 & 115 & $17 \%$ & $18 \%$ & $45 \%$ & $4 \%$ & $16 \%$ & 66 & $15 \%$ & $20 \%$ & $49 \%$ & $5 \%$ & $12 \%$ & $100 \%$ & 49 & $20 \%$ & $16 \%$ & $41 \%$ & $2 \%$ & $20 \%$ & $100 \%$ \\
\hline
\end{tabular}

Notes: "\#" means the total number of people within each group. "+" stands for an increase in ranking; "-" implies a decrease in ranking. "Same" means that scholars remain at the same department. "Diff. Dept." refers to those who are at different departments that are similarly ranked with their previous institutions (within five ranks). "Non-PhD" refers to the proportion of those who moved to non-PhD-granting institutions. 
shows whether they moved to a non-PhD-granting institution. For those who changed institutions but remained at a US PhD-granting department, table 2 also shows whether the 2017 department was ranked higher, lower, or the same as the 2002 department by using the 2017 ranking of political science departments in US News and World Report. ${ }^{15}$
Although we could not directly address this issue, table 3 provides relevant evidence on gender differences that cannot be explained by differences in the proportion of males and females in different cohorts. We examined the proportion of men in each cohort with $\mathrm{R} 1$ jobs who became full professors compared to the proportion of women in the same cohort who

The table shows that except for the earliest cohorts, within each cohort, women were less likely to be full professors and more likely to be assistant professors than men. Among all cohorts, $82 \%$ of men were full professors whereas only 66.9\% of women were full professors.

The data show that the majority of non-emeritus faculty who were employed at a $\mathrm{PhD}$-granting department in 2002 were at that same university in 2017. Remarkably, among those who moved, movement was as likely to a more prestigious as to a less prestigious department. The same is true for both men and women. Also, men and women were roughly equally likely to move to a job that was not at a $\mathrm{PhD}$-granting university. Moreover, younger cohorts-who are still in the process of establishing themselves within the profession-had higher proportions of taking positions at non-PhD-granting departments.

\section{Status Change in Terms of Tenure and Promotions}

Older cohorts had fewer women in terms of both those teaching at $\mathrm{PhD}$-granting departments and the pool of $\mathrm{PhDs}$ from which such faculty are drawn. This has a downstream effect as most full professors are men, largely because they disproportionately come from older cohorts. A key question is whether these representational differences can be explained over time by gender differences in $\mathrm{PhD}$ production at universities that provide most of the faculty who teach at PhD-granting universities. According to Brown et al. (2017), female PhD students comprised nearly half of the student body at the largest 20 departments in 2012; however, this level of gender representation is not characteristic of earlier cohorts. became full professors. The table shows that except for the earliest cohorts, within each cohort, women were less likely to be full professors and more likely to be assistant professors than men. Among all cohorts, $82 \%$ of men were full professors whereas only $66.9 \%$ of women were full professors. In the youngest cohort, $50.7 \%$ of men were full professors whereas only $39.6 \%$ of women were full professors. ${ }^{16}$ Within cohorts, women were overrepresented at the associate-professor rank.

\section{ROLE OF CITATION COUNTS}

We now discuss the role of citation counts in both present and past placements. We conjectured that those with lower citation counts within each cohort would begin and end at relatively lowerranked institutions. Within each cohort, we divided the faculty in the MGF dataset into three groups (i.e., the upper, middle, and bottom thirds of citation counts) based on the MGF lifetime citation count using data from the Web of Science. We also categorized the data by gender. ${ }^{17}$

We compared faculty in the upper third of citation ranks to those in the lower third, vis-à-vis the average rank of the department at which they taught ca. 2002, on a scale from 1 to 97 in table 4 , using US News and World Reports departmental rankings. Lower numbers indicate higher-ranked departments. As shown in table 4, those in the upper third of their cohorts, regarding their citation

Table 3

2017 Rank of Non-Emeritus Faculty in the 2002 MGF Dataset, by Cohort, with Further Breakdown by Gender

\begin{tabular}{|c|c|c|c|c|c|c|c|c|c|c|c|c|}
\hline & \multicolumn{4}{|c|}{ Total } & \multicolumn{4}{|c|}{ Male } & \multicolumn{4}{|c|}{ Female } \\
\hline & Assistant & Associate & Full & Total & Assistant & Associate & Full & Total & Assistant & Associate & Full & Total \\
\hline $1960-64$ & $0.0 \%$ & $2.6 \%$ & $97.4 \%$ & $100 \%$ & $0.0 \%$ & $2.6 \%$ & $97.4 \%$ & $100 \%$ & $0.0 \%$ & $0.0 \%$ & $0.0 \%$ & $0 \%$ \\
\hline $1965-69$ & $0.9 \%$ & $7.1 \%$ & $92.0 \%$ & $100 \%$ & $1.0 \%$ & $7.9 \%$ & $91.1 \%$ & $100 \%$ & $0.0 \%$ & $0.0 \%$ & $100.0 \%$ & $100 \%$ \\
\hline $1970-4$ & $1.1 \%$ & $8.5 \%$ & $90.4 \%$ & $100 \%$ & $1.3 \%$ & $9.4 \%$ & $89.3 \%$ & $100 \%$ & $0.0 \%$ & $3.4 \%$ & $96.6 \%$ & $100 \%$ \\
\hline 1975-79 & $0.8 \%$ & $6.8 \%$ & $92.4 \%$ & $100 \%$ & $0.5 \%$ & $6.4 \%$ & $93.1 \%$ & $100 \%$ & $2.0 \%$ & $8.2 \%$ & $89.8 \%$ & $100 \%$ \\
\hline $1980-84$ & $0.0 \%$ & $13.3 \%$ & $86.7 \%$ & $100 \%$ & $0.0 \%$ & $11.3 \%$ & $88.7 \%$ & $100 \%$ & $0.0 \%$ & $20.0 \%$ & $80.0 \%$ & $100 \%$ \\
\hline 1985-89 & $0.3 \%$ & $17.3 \%$ & $82.4 \%$ & $100 \%$ & $0.0 \%$ & $16.8 \%$ & $83.2 \%$ & $100 \%$ & $1.3 \%$ & $18.7 \%$ & $80.0 \%$ & $100 \%$ \\
\hline 1990-94 & $1.0 \%$ & $26.8 \%$ & $72.2 \%$ & $100 \%$ & $0.7 \%$ & $23.7 \%$ & $75.5 \%$ & $100 \%$ & $1.7 \%$ & $33.9 \%$ & $64.4 \%$ & $100 \%$ \\
\hline 1995-99 & $3.1 \%$ & $33.6 \%$ & $63.3 \%$ & $100 \%$ & $2.1 \%$ & $29.2 \%$ & $68.7 \%$ & $100 \%$ & $5.3 \%$ & $42.9 \%$ & $51.9 \%$ & $100 \%$ \\
\hline Post-2000 & $6.6 \%$ & $47.1 \%$ & $46.3 \%$ & $100 \%$ & $2.7 \%$ & $46.6 \%$ & $50.7 \%$ & $100 \%$ & $12.5 \%$ & $47.9 \%$ & $39.6 \%$ & $100 \%$ \\
\hline
\end{tabular}




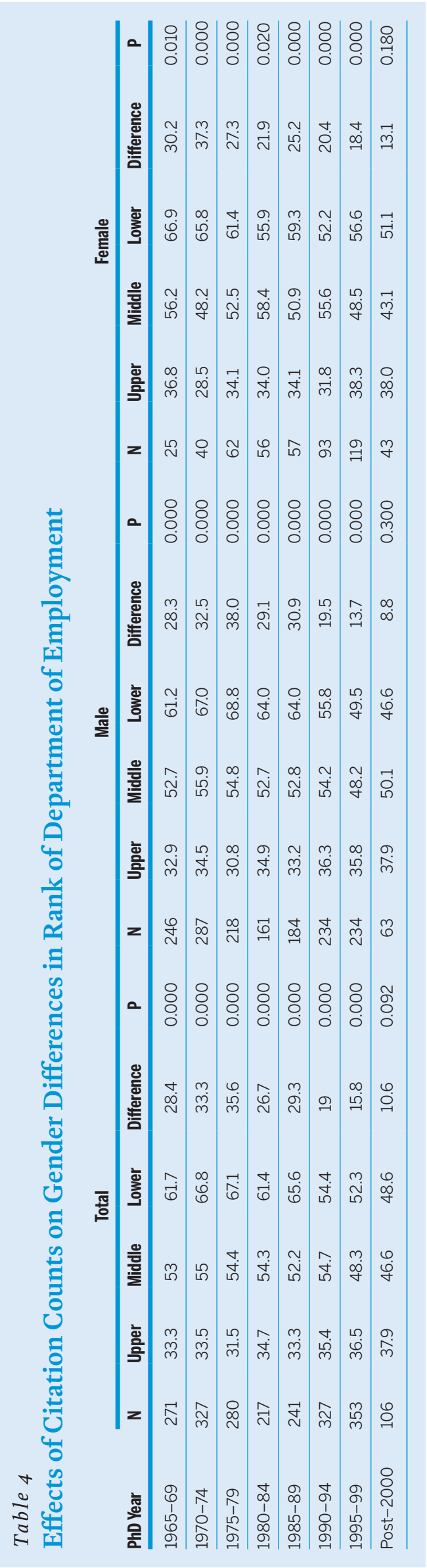

counts, were located at considerably higher-ranked universities in 2002 than those in the bottom third. ${ }^{18}$ The difference-of-means test for each cohort was statistically significant for all except one cohort. ${ }^{19}$

Thus, citation counts are important in explaining differences in placement. Moreover, these statistically significant differences in placement ranking, according to citation counts, hold separately for both men and women. Similarly, Grofman (2009) demonstrated that for University of California political science faculty, citation counts are a good predictor of salary levels once the date of $\mathrm{PhD}$ is taken into account.

We expect that table 4 understates the importance of citation counts for professional success at the research-university level because our dataset includes only those who already had a job at a PhD-granting department. We expected that the average citation differences between those employed at $\mathrm{PhD}$-granting departments and those with other types of political science jobs would be significant. However, we also think that the causal arrow goes in both directions because those who are not hired at research-oriented institutions will have more difficulty obtaining the resources needed to publish and, thus, potentially be cited.

The key question of interest is whether highly cited women (i.e., the top third, relative to their cohort) were as highly placed as comparably highly cited men in that cohort. A similar question is asked about those in the bottom and middle thirds of citation counts relative to their cohort overall. We found a mixed pattern. Looking at the upper citation group, for example, the differences were not that compelling-and basically "noise." Highly cited women were as likely to be highly placed as highly cited men. Similarly, although there was slightly more variation, less cited women (i.e., the bottom third, relative to their overall cohort citation counts) were essentially as likely to be highly placed as men of comparable citation status in their cohort. Among the middle-third citation category, however, we found substantial evidence of gender differences. In summary, while women seem to do as well as men among scholars who are above or below average in terms of citation counts relative to their cohort, it seems easier for middle-ranked men, vis-à-vis citations, to be placed higher than women with comparable citation counts. Moreover, as discussed above, women are less likely to be cited than men in their respective cohorts, and this citation gender gap seems to be increasing. As such, it is possible that the gender gap in placement and promotion, which is influenced by citation counts, may also increase.

\section{DISCUSSION}

This article focuses on questions drawn from our integration of 2017 data with the 2002 MGF dataset. We found extensive turnover in terms of retirements and deaths among the set of scholars identified in 2002 as being employed at an R1 US political science department. During this 15 -year period, there was a strong generational shift, which is reflected in the present cohort composition of R1 political science departments compared to 2002. There is no clear pattern of upward or downward movement in prestige of institution between 2002 and 2017 among those in the 2002 dataset who were alive and non-emeritus in 2017 . However, we found that citation counts (ca. 2002) relative to those among an individual's own cohort were useful in predicting the prestige level of the institution that a scholar taught at in 2002, 
as well as the likelihood of a shift to a more or less prestigious institution in 2017.

Regarding gender effects, we examined those 2002 faculty who still had non-emeritus status in 2017; when we controlled for cohort, there was no statistically significant gender differences in retention at a $\mathrm{PhD}$-granting university. There also were no significant gender differences regarding whether these faculty stayed at a non-R1 institution; however, there were significant study, Zigerell (2015) suggested that much of the observed gender gap is due to gender differences in citations among only relatively few of the most highly cited articles. ${ }^{24}$

We want to conclude this article on an optimistic note. Women are becoming an increasing proportion of faculty at $\mathrm{PhD}$-granting political science departments. Indeed, if present trends continue, it is not unreasonable to expect gender parity in hiring new faculty in the not-too-distant future.

\section{Women are becoming an increasing proportion offaculty at PhD-granting political science departments. Indeed, if present trends continue, it is not unreasonable to expect gender parity in hiring new faculty in the not-too-distant future.}

differences based on cohort. ${ }^{20}$ Moreover, looking at the full dataset of 2017 faculty, we found that male scholars in younger cohorts were more likely to advance to full professorship than their female peers. These differences were not as strong in older cohorts, but this may be due to the fact that there were very few women in those cohorts to begin with.

When we added citation-count data, scholars with higher citation counts relative to their cohort were more likely to be at and stay at more highly ranked departments; this was true for both men and women. However, women in the middle-third group of citation counts relative to their cohort seemed to be disadvantaged in department placement relative to the men in their cohort. ${ }^{21}$

Controlling for citations still may understate gender effects. Citation counts may suffer from gender bias as measures of achievement and visibility. Much of the gender bias in academia (i.e. tenure, promotions, etc.) stems from the gender bias in citation counts. Because female scholars have fewer citations, this gender citation gap makes women less likely (or take longer) to be hired and promoted, less likely to achieve full professorship, and more likely to leave academia (Hesli, Lee, and Mitchell 2012; Maliniak, Powers, and Walter 2013; Xu 2008).22 As such, finding a way to fix the gender bias in citation counts in the discipline can help alleviate much of the downstream gender bias.

A note of caution must be added to a too-casual reading of this literature. In particular, we argue for the importance of a control for the date of PhD. ${ }^{23}$ We might expect that the men who publish in a given journal, on average, are older than the women who publish there, simply because of the historical gender structure of the profession and the fact that those who publish continue to include older (and often frequently publishing) as well as younger scholars. However, ceteris paribus, we do not expect the number of citations for work in a journal by relatively younger scholars to be as high as citations to work in that same journal by more senior scholars-for example, those whose work was read by many present faculty members since their graduate school days. How much this potential confound matters can be understood only by controlling for cohort when making gender comparisons. It well may turn out that this type of potential confound, although real, is simply too minor to explain the considerable gender citation differences often found. However, in reanalyzing the Mitchell, Lange, and Brus (2013)

\section{SUPPLEMENTARY MATERIAL}

To view supplementary material for this article, please visit https://doi.org/10.1017/S1049096519000490

\section{ACKNOWLEDGMENTS}

The authors thank the anonymous reviewers at PS: Political Science $\mathcal{E}$ Politics and the editors for helpful feedback and comments.

\section{NOTES}

1. This study of Masuoka, Grofman, and Feld (2007a) was an update of work by Klingemann (1986) and Klingemann, Grofman, and Campagna (1989).

2. See appendix A for information on errors in the original Masuoka, Grofman, and Feld dataset.

3. See appendix B for a discussion of our method of gender coding and tables showing 2017 status and gender for scholars in the 2002 MGF database. We could not code for gender in a few cases; these individuals were omitted in tables in which reference is made to gender.

4. See appendices C and D, respectively, for rank of faculty ca. 2002 and the list of institutions for which we could calculate the department prestige level.

5. See appendix $\mathrm{E}$ for details on how we found information on each faculty member, how we coded the current status of each, and how missing information was handled.

6. Although this dataset is limited to those who were (ca. 2002) or are (ca. 2017) employed at PhD-granting institutions-and the results may not be representative of overall patterns of promotion and tenure in US academia-we note that those at $\mathrm{PhD}$-granting departments are a substantial proportion of all political science faculty. Despite the limited number of these departments, they are, on average, much larger than the equivalent at colleges and in twoyear programs. Moreover, even if this were an unrepresentative sample, it is a large and important dataset in its own right, especially because those at $\mathrm{PhD}$-granting departments comprise the majority of political scientists who are actively publishing in research journals and who train most of the profession. We view this data as complementary to the data referenced by Hochschild et al. (2017) in a letter to the PS: Political Science \& Politics editor. Hochschild's data, from the Digest of Education Statistics and APSA reports, address the profession as a whole.

7. More than half of the $1970-74$ cohort no longer has a full-time academic position; the majority of those in earlier cohorts, especially those with $\mathrm{PhDs}$ before 1965 , is even more decimated. Of course, there is a dramatic decrease in the proportion of deceased and emeritus faculty as we move from older to younger cohorts. (The data are omitted due to limited space; see online appendix $\mathrm{F}$ for details and the full table.)

8. See online appendix $\mathrm{G}$ for details.

9. See appendix $\mathrm{H}$ for more information about the list of professors, the nontenured people, those who went into administration, and those who pursued non-academic routes.

10. See appendix I.

11. We must be careful in interpreting this percentage because all women in this cohort are assistant professors, and not all assistant professors gain tenure. Thus, if there are gender differences in the likelihood of achieving tenure (see table 4), the proportion of women from this cohort may change. 
12. Data from the PS 400 (Kim and Grofman 2019) shows that, based on the average citation numbers by gender among the tenured or tenure-track faculty at $\mathrm{PhD}$-granting departments in 2017, men are almost always cited more than women in virtually all cohorts.

13. However, not all of the studies with these conclusions control for age effects. For example, we expect that book editors are disproportionately senior faculty and thus disproportionately male. However, how important such potential confounds actually are-if at all-can be answered only by further empirical work.

14. The table includes chairs, chancellors, and deans.

15. Available at www.usnews.com/best-graduate-schools/top-humanities-schools/ political-science-rankings. See appendix J for further details on the coding of university ranking.

16. Similarly, in a dataset developed by the APSA Presidential Task Force on Women's Advancement, Brown et al. (2017) found that women comprise only one fifth of full professors but are a much larger proportion of assistant professors. Overall, women are underrepresented in the academy (Ceci and Williams 2011; Van Anders 2004) as well as in publishing and citation counts (Mathews and Andersen 2001; Mitchell, Lange, and Brus 2013; Teele and Thelen 2017; cf. Zigerell 2015) and assigned readings in course syllabi (Hardt et al. forthcoming).

17. Many initiatives have begun to promote equal gender representation. See appendix $\mathrm{K}$ for information on these initiatives.

18. The pattern is essentially monotonic across the three categories.

19. This is the youngest cohort, in which we expect to find the least difference because they may have been hired primarily on "promise."

20. See appendix $\mathrm{L}$ for the full table.

21. In this context, we note that Grofman (2009) found that gender differences in faculty salaries for political scientists teaching at the University of California essentially disappeared when we controlled for both date of $\mathrm{PhD}$ and citation count.

22. Citation counts have grown in importance in tenure evaluations, but we still think that citation-count differences in self-citations would not matter that much because such data can be generated in a way that excludes self-citation. However, that dismissal misses the point that failure to self-cite violates the academic equivalent of Rabbi Hillel's injunction about self-abnegation: "If I am not for myself, who am I for?" As Wuffle (personal communication, April 1, 2018) pointed out: "Those who do not cite themselves fail to call attention to papers of theirs that might be cited by others, thus diminishing their likely professional visibility." Of course, when looking at citation counts by gender, we also must consider publication counts (especially in terms of cohort effects that are linked to gender) because those with many publications will be able to easily identify relevant publications of their own that they might cite.

23. In work outside of political science, Morgan (1998) called attention to the potential for age and related effects to be confounding with gender.

24. In particular, ceteris paribus, articles by "famous folks" are more likely to be read, and more of these folks are men because there were more men during the earlier history of the profession. Thus, the citation "edge" that men appear to have may be due to an age-based "halo" effect.

\section{REFERENCES}

Brown, Nadia, Mala Htun, Frances Rosenbluth, Kathleen Thelen, and Denise Walsh. 2017. "How Are Women Political Scientists Doing? A Report from the APSA Committee for the Status of Women in the Profession and the Thelen Presidential Taskforce." Comparative Newsletter 27 (1): 81-3.
Ceci, Stephen J., and Wendy M. Williams. 2011. "Understanding Current Causes of Women's Underrepresentation in science." Proceedings of the National Academy of Sciences, 201014871.

Fowler, James H., Bernard Grofman, and Natalie Masuoka. 2007. "Social Networks in Political Science: Hiring and Placement of PhDs, 1960-2002." PS: Political Science \& Politics 40 (4): 729-39.

Grofman, Bernard. 2009. "Determinants of Political Science Faculty Salaries at the University of California." PS: Political Science \& Politics 43 (4): 719-27.

Hardt, Heidi, Amy Erica Smith, Hannah June Kim, and Philippe Meister. Forthcoming. "The Gender Readings Gap in Political Science Graduate Training." Journal of Politics.

Hesli, Vicki L., Jae Mook Lee, and Sara McLaughlin Mitchell. 2012. "Predicting Rank Attainment in Political Science: What Else Besides Publications Affects Promotion?" PS: Political Science \& Politics 45 (3): 475-92.

Hochschild, Jennifer, Rogers M. Smith, Sara L. Parker, Michelle Deardorff, and Steven Rathgeb Smith. 2017. "Mismatch between (Some of) APSA and (Some) Political Scientists?" PS: Political Science \& Politics 50 (4): 917-20.

Kim, Hannah June, and Bernard Grofman. 2019. "The Political Science 400: With Citation Counts by Cohort, Gender, and Subfield." PS: Political Science \& Politics.

Klingemann, Hans-Dieter. 1986. "Ranking the Graduate Departments in the 1980s: Toward Objective Qualitative Indicators.” PS: Political Science \& Politics 19 (3): $651-61$.

Klingemann, Hans-Dieter, Bernard Grofman, and Janet Campagna. 1989. “The Political Science 40o: Citations by $\mathrm{PhD}$ Cohort and by $\mathrm{PhD}$-Granting Institution." PS: Political Science \& Politics 22 (2): 258-70.

Maliniak, Daniel, Ryan Powers, and Barbara F. Walter. 2013. "The Gender Citation Gap in International Relations." International Organization 67 (4): 889-922.

Masuoka, Natalie, Bernard Grofman, and Scott L. Feld. 2007a. "The Political Science 400: A 20-Year Update." PS: Political Science \& Politics 40 (1): 133-45.

Masuoka, Natalie, Bernard Grofman, and Scott L. Feld. 2007b. "The Production and Placement of Political Science PhDs, 1902-200o." PS: Political Science $\mathcal{E}$ Politics 40 (2): 361-66.

Masuoka, Natalie, Bernard Grofman, and Scott L. Feld. 2007c. "Ranking Departments: A Comparison of Alternative Approaches." PS: Political Science $\mathcal{E}$ Politics 40 (3): 531-37.

Mathews, A. Lanethea, and Kristi Andersen. 2001. "A Gender Gap in Publishing? Women's Representation in Edited Political Science Books." PS: Political Science \& Politics 34 (1): 143-47.

Mitchell, Sara McLaughlin, Samantha Lange, and Holly Brus. 2013. "Gendered Citation Patterns in International Relations Journals." International Studies Perspectives 14 (4): 485-92.

Morgan, Laurie A. 1998. "Is the Gender Citation Gap in International Relations Driven by Elite Papers?" American Sociological Review (1998): 479-93.

Teele, Dawn Langan, and Kathleen Thelen. 2017. "Gender in the Journals: Publication Patterns in Political Science." PS: Political Science \& Politics 50 (2): 433-47.

Van Anders, Sari M. 2004. "Why the Academic Pipeline Leaks: Fewer Men than Women Perceive Barriers to Becoming Professors." Sex Roles 51 (9-10): 511-21.

$\mathrm{Xu}$, Yonghong Jade. 2008. "Gender Disparity in STEM Disciplines: A Study of Faculty Attrition and Turnover Intentions." Research in Higher Education 49 (7): 607-24.

Zigerell, L. J. 2015. "Is the Gender Citation Gap in International Relations Driven by Elite Papers?" Research \& Politics 2 (2): 2053168015585192. 